\title{
Sublingual microcirculation: a case report
}

\author{
Jonas D. Scheuzger ${ }^{*}$ (D, Anna Zehnder, Desirée Yeginsoy and Martin Siegemund ${ }^{*}$
}

\begin{abstract}
Introduction: Sublingual microcirculation monitoring is suitable for bedside use in critically ill patients. We present a case in which severely impaired sublingual microcirculation was the first alarming sign of an early deterioration of the patient's medical situation.
\end{abstract}

Case presentation: This is the case of a 58-year-old white woman admitted to our intensive care unit after the removal of parts of her small intestine due to a volvulus. Her microcirculation was checked the day after surgery in terms of an ongoing study and predicted a massive deterioration of her clinical situation.

Conclusions: This case highlights the potential value of monitoring the microcirculation in critically ill patients. Two full hours could have been saved for diagnostic workup and earlier treatment had we considered the impaired microcirculation alone as a warning sign. Regardless of the supposed cause, impaired microcirculation should alert the responsible physician and should be followed by a diagnostic workup. Sublingual microcirculation monitoring can be useful in intensive care units to detect a deteriorated microcirculation earlier than with standard monitoring.

Keywords: Microcirculation/physiology, Monitoring, physiologic/methods, Colectomy, Sepsis, Critical illness, Intensive care units

\section{Introduction}

Hemodynamic and laboratory parameters are monitored continuously in intensive care patients. Although an intact microcirculation is the key player in tissue metabolism, evaluating microcirculation is not part of daily routine in the intensive care unit (ICU). Peripheral oxygen saturation and serum lactate only provide indirect evidence of the microcirculatory system. Impaired microcirculation results in attenuated metabolic blood supply, which can cause cell damage. More importantly, microcirculatory flow (MCF) can react independently of global circulatory parameters (for example, blood pressure, vasopressors) [1,2].

Sublingual incident dark field (IDF) imaging provides physiological insight into the microcirculation in real time. The CytoCam-IDF (Braedius Medical, Huizen, the Netherlands) is a handheld device available for bedside use [3]. The CytoCam records videos non-invasively through the mucosa (for example, in the sublingual

\footnotetext{
*Correspondence: jonasdominic.scheuzger@usb.ch;

Jonas.scheuzger@gmail.com; martin.siegemund@usb.ch

This work was performed at the University Hospital Basel, Switzerland Department for Anesthesia, Surgical Intensive Care, Prehospital Emergency Medicine and Pain Therapy, University Hospital Basel, Spitalstrasse 21, CH-4031 Basel, Switzerland
}

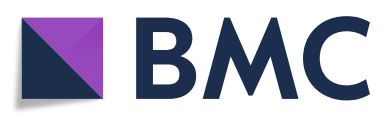

(c) The Author(s). 2019 Open Access This article is distributed under the terms of the Creative Commons Attribution 4.0 International License (http://creativecommons.org/licenses/by/4.0/), which permits unrestricted use, distribution, and

reproduction in any medium, provided you give appropriate credit to the original author(s) and the source, provide a link to the Creative Commons license, and indicate if changes were made. The Creative Commons Public Domain Dedication waiver (http://creativecommons.org/publicdomain/zero/1.0/) applies to the data made available in this article, unless otherwise stated.

\section{Methods}

We regularly perform CytoCam measurements in critically ill patients as a part of ongoing studies in our department. We used the latest third-generation handheld microscope CytoCam (Braedius, Huizen, Netherlands). This handheld microscope currently provides the best optical resolution compared to other devices and is suitable for bedside use [5]. The device consists of a pen-like probe incorporating IDF illumination, a principle originally introduced by Sherman et al. (Fig. 1) [6]. In this case, we 


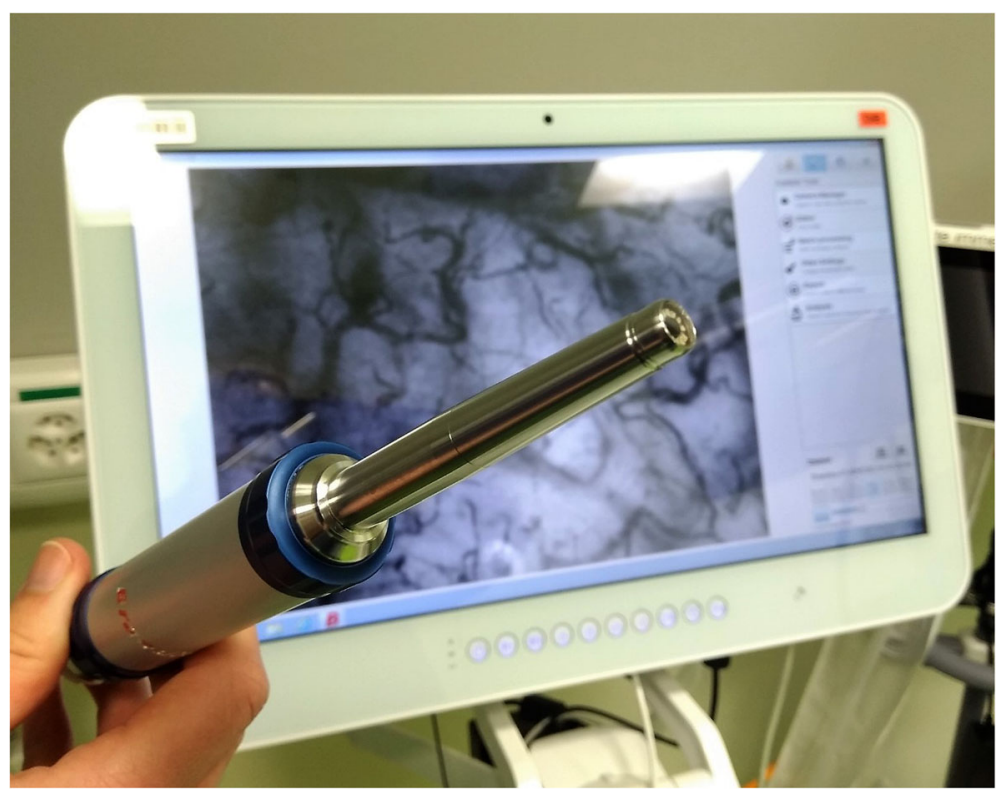

Fig. 1 CytoCam device at our intensive care unit

took five videos and used the three best records according to the microcirculation image quality score (MIQS) [7] for offline analysis. The careful application of the tip-like microscope in the sublingual fold avoids pressure artefacts. We used the microvascular flow index (MFI) and De Backer's Score [8] to describe semi-quantitative parameters like total vessel density (TVD), proportion of perfused vessels (PPV), and perfused vessel density (PVD). The operator attended a training course, and two independent observers performed offline analyses.

\section{Case presentation}

A 58-year-old white woman, weighing $55 \mathrm{~kg}$ and with a body mass index of 23, was admitted to our hospital suffering from general weakness, coughing with purulent sputum, fever, and nausea. She presented in a stable general condition, except for schizophrenia with mild cognitive impairment. Prior to admission, she received clozapine $(250 \mathrm{mg} /$ day $)$ for schizophrenia. She had no other relevant diagnoses and interventions in her past medical history. She lived in an assisted living facility and was employed in a protected workplace program. She was able to take care of herself and was able to perform daily tasks on her own (for example, grocery shopping). She has no direct relatives and was raised in a children's home. On admission, she was awake with a Glasgow Coma Scale (GCS) of 15 and was temporal, local, and autopsychic oriented. She showed no neurological deficiency. She was hemodynamically stable with heart rate of 100 beats per minute (bpm), blood pressure of $99 / 70 \mathrm{mmHg}$, respiratory rate of $14 /$ minute, and body temperature of $38.9^{\circ} \mathrm{C}$. She had signs of mild dyspnea, coughing, and wheezing at auscultation. Her abdomen was soft without tenderness on palpation. Bowel sounds were equally present. An influenza screening test was negative. Urinary and blood cultures showed no bacterial infection. Blood samples on admission showed an elevated C-reactive protein (CRP) of $39 \mathrm{mg} / \mathrm{L}$, leukocytes of $9.9 \mathrm{~g} / \mathrm{L}$, and a lactate level of $2.1 \mathrm{mmol} / \mathrm{L}$. Creatinine clearance, liver function, electrolytes, and counted blood cells were all within normal ranges. With a tobacco smoking history of 40 pack-years, she was now treated for exacerbated chronic obstructive pulmonary disease and antibiotic therapy with intravenously administered amoxicillin/clavulanic acid (1.2 g three times a day). Prednisone $(50 \mathrm{mg} /$ day) was also started. Two days after admission, she suffered acute vomiting and presented a diffuse pressure-resistant and distended abdomen. Abdominal computed tomography showed a volvulus in the small intestine, $20 \mathrm{~cm}$ from the ileocecal valve, confirming the indication for emergency laparotomy (Fig. 2).

After surgery, she arrived in the ICU under sedation with propofol ( $80 \mathrm{mg} /$ hour) and fentanyl $(0.05 \mathrm{mg} /$ hour $)$, decreased bowel sounds, and normal cardiopulmonary parameters. Initially, she received $0.5 \mathrm{mg}$ haloperidol as prophylaxis for delirium. She was continuously administered noradrenaline $(0.34 \mu \mathrm{g} / \mathrm{kg}$ per minute) to maintain circulation and Ringer's acetate for volume support. We treated her respiratory infection with piperacillin/tazobactam ( $13.5 \mathrm{~g} /$ day). For volume support, she received $5000 \mathrm{ml}$ Ringer's acetate during the first 24 hours. Her urinary output was supported with furosemide $(35 \mathrm{mg})$ over the first 24 hours. In addition, she received anticoagulation with dalteparin (5000 IU). 


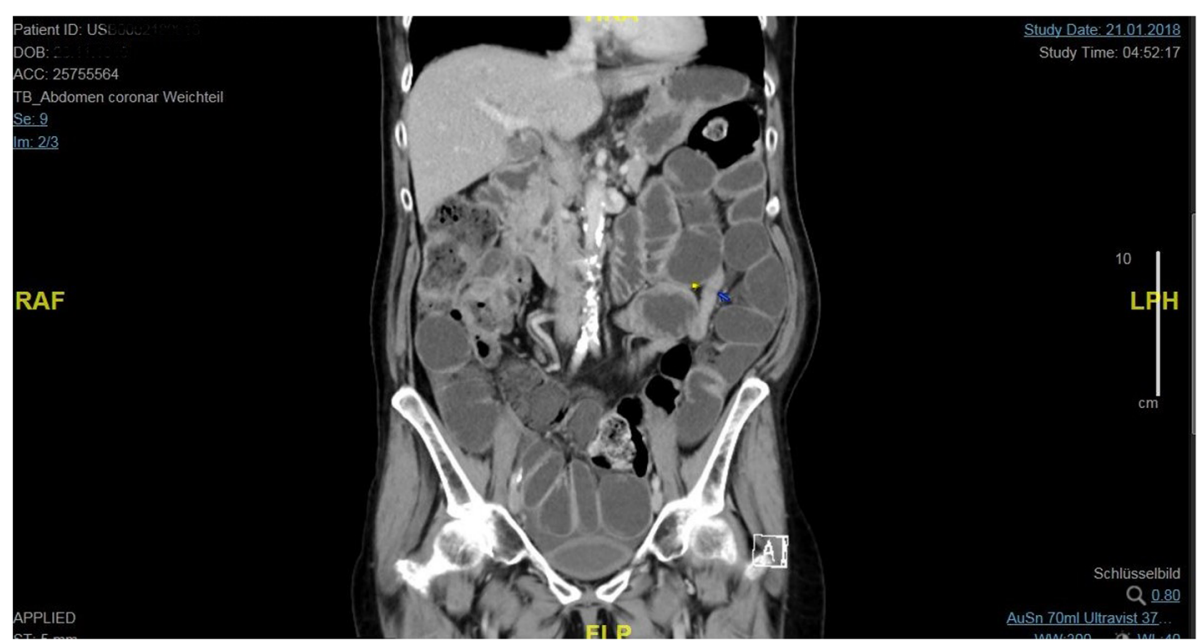

Fig. 2 Frontal with triple contrast shows a distended small intestine in the left upper abdomen. Caliber jump of the intestine is marked with a yellow and blue dot

The initial period was uneventful. Although ventilator weaning was intended for our patient and sedation was reduced, she remained dependent on positive end-expiratory pressure and extubating was not possible. Under volume therapy and a positive fluid balance of 4 liters the next morning, noradrenaline could be partially reduced and maintained at $0.25 \mu \mathrm{g} / \mathrm{kg}$ per minute. Her first post-surgery blood check at $5 \mathrm{p}$.m. showed a CRP of 179 $\mathrm{mg} / \mathrm{L}$, leukocyte count of $17 \times 10^{9} / \mathrm{L}$, hemoglobin at $81 \mathrm{~g} /$ $\mathrm{L}$, creatinine at $118 \mu \mathrm{mol} / \mathrm{L}$, and serum lactate at 1.5 $\mathrm{mmol} / \mathrm{L}$. She was slightly agitated and received a total 4.5 mg haloperidol over 24 hours for delirium treatment.

In the morning, we included her in a study and routinely measured her microcirculation. The microcirculatory measurement revealed an almost absent MCF (Fig. 3, see also Supplementary content - Additional file 1: Video S1, Impaired sublingual microcirculation of the described case, in comparison with Additional file 2: Video S2, intact microcirculation of a member of the study team). In addition, offline analysis showed an MFI of far below normal (2.6 is the accepted threshold) for all three recordings. Even in the recording with the most perfused vessels (Table 1), less than $25 \%$ of the vessels were perfused (PPV).

Except for the altered microcirculation, circulatory and laboratory parameters showed no clear indication for a deterioration of the medical situation. Post-surgical CRP and leukocytes were expected to be high. Infrared blood oxygen saturation $\left(\mathrm{SpO}_{2}\right)$ inconsistently showed low values between 50 and $90 \%$ by a fingertip detector. We initially interpreted this to be a malfunction due to a cold periphery.

Because of the normal hemodynamic measurements, we chose an expectant strategy and increased intravenous fluid administration. Arterial blood gas analysis showed only moderate rise of lactate levels from 1.5 to $3 \mathrm{mmol} / \mathrm{L}$ (Table 2). A laboratory examination 80 minutes later indicated a rapid deterioration of the situation with a lactate level of $5.4 \mathrm{mmol} / \mathrm{L}$ and a decreased hemoglobin level of $59 \mathrm{~g} / \mathrm{L}(36.6 \mathrm{mmol} / \mathrm{L})$.
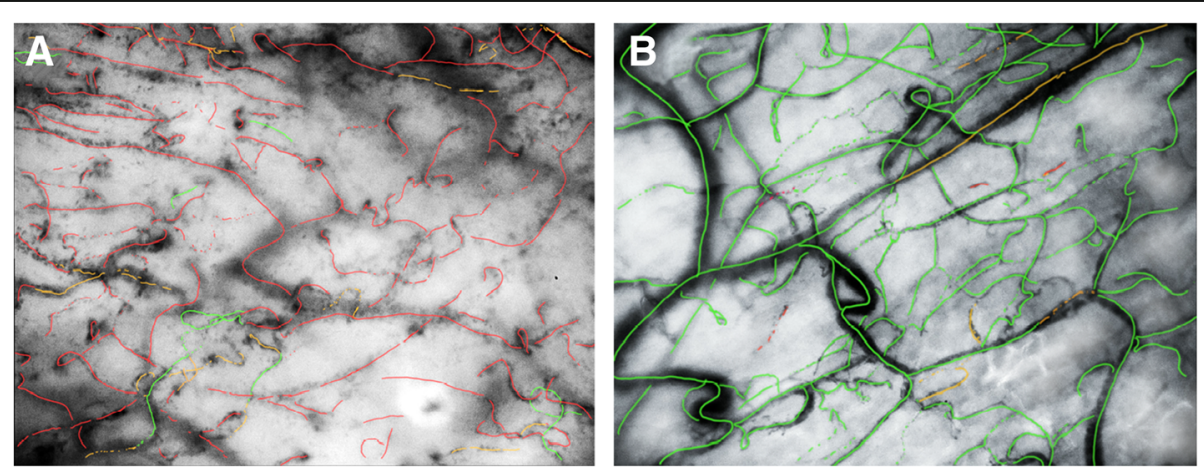

Fig. 3 a. Impaired microcirculation represented by the case described (recording 1) versus $\mathbf{b}$ normal microcirculation. The images were extracted from the video recording and colorized according to the original video presentation for a better visualization with: red = no flow, orange $=$ intermittent flow, green $=$ normal flow 
Table 1 Flow variables of the three selected recordings

\begin{tabular}{llll}
\hline Parameters & Recording 1 & Recording 2 & Recording 3 \\
\hline MFI & 0.3 & 0.5 & 0.75 \\
VD (De Backer) & 9.6 & 6.6 & 8.1 \\
PVD (De Backer) & 0.49 & 1.11 & 1.98 \\
PPV (De Backer), \% & 5.33 & 16.7 & 24.2 \\
MIQS & 1 & 1 & 1 \\
\hline
\end{tabular}

$M F I$ microcirculatory flow index, MIQS microcirculatory image quality score, PPV proportion of perfused vessels, PVD perfused vessel density, $V D$ vessel density

Transfusion of 2 units of packed cells was initiated, and an arterial blood gas sample was drawn after 30 minutes. Transthoracic ultrasound showed a hyperdynamic, underfilled left ventricle, and abdominal ultrasound gave no further information. She underwent an immediate surgical re-evaluation.

The laparotomy showed a dilated and visually ischemic descending colon down to the sigmoid. The previous ileocecal anastomosis was still intact and the ileum was vital. The entire colon was removed, and an ileostomy was implanted in her abdominal wall. A third look surgery a few days later showed an intact and vital remaining bowel. Postoperative microcirculation and blood samples returned to normal, and she recovered slowly without further complications from her severe condition. She could be discharged from our hospital 4 weeks after admission and returned to her domestic environment. In the follow-up consultation after 6 months at our hospital she refused a retrocession of the stoma. She managed the daily care of the ileostomy by herself and felt comfortable with it. Except for the permanent ileostomy, she did not have any residual symptoms from the incident and integrated herself in the daytime routine. No further consultation was planned.

\section{Discussion}

To the best of our knowledge, this is the first report of severely impaired sublingual microcirculation in a patient, clearly indicating a deterioration of the clinical situation, prior to standard hemodynamic monitoring and regular blood samples. This case demonstrates how observation of the microcirculation in a severely ill patient can act as an advanced warning compared to standard hemodynamic monitoring and regular blood samples. The alarm aspect of detecting early deterioration of the microcirculation is analogous to the old safety practice of using canaries in coal mines to serve as an early warning of an elevated level of carbon monoxide. If impaired microcirculation had been ascribed greater attention in this case, a minimum of 2 hours could have been saved for diagnostic workup (Fig. 4). However, it is unclear at which point in time the microcirculation started to deteriorate before the measurement.

Although microcirculatory measurement is not a routine diagnostic tool for any specific type of disease, an impaired microcirculation should not be overlooked. Tissue oxygenation takes place by direct exchange of oxygen from erythrocytes to the endothelial surface of small vessels and capillaries of the microcirculatory system. Previous studies in patients with sepsis [9] and cardiac [10] patients have demonstrated that persistent MCF alterations unresponsive to therapy are independently associated with adverse outcome. Despite intact macrohemodynamic parameters (for example, blood pressure and cardiac output), tissue hypoxia due to MCF collapse or dysregulation occurs in patients with shock $[1,2]$.

Early detection of a massive deterioration of the MCF before standard monitoring that was able to indicate this degree of severity may be an accidental finding. Great caution is advised, and a generalization without further studies cannot be made from a case report. However, restoration of

Table 2 Monitoring values

\begin{tabular}{|c|c|c|c|c|}
\hline Parameters & 1 BS $(08: 20)$ & 2 BS (10:30) & 3 BS (11:50) & $4 \mathrm{BS}(12: 20)$ \\
\hline Lactate (mmol/L) & 1.5 & 3 & $5.4^{\uparrow}$ & $6.5^{\uparrow}$ \\
\hline Hemoglobin ( $\mathrm{g} / \mathrm{L}$ ) & 82 & 82 & $59^{\uparrow}$ & $59^{\uparrow}$ \\
\hline $\mathrm{pH}$ & $7.36^{\downarrow}$ & $7.36^{\downarrow}$ & $7.346^{\downarrow}$ & $7.321^{\downarrow}$ \\
\hline $\mathrm{HCO}_{3}(\mathrm{mmol} / \mathrm{L})$ & 24.7 & 23.8 & 21.1 & 19.9 \\
\hline $\mathrm{PCO}_{2}(\mathrm{kPa})$ & $5.9^{\uparrow}$ & $5.6^{\uparrow}$ & 5.2 & 5.3 \\
\hline $\mathrm{PO}_{2}(\mathrm{kPa})$ & 14.7 & 15.8 & 16.9 & 17.1 \\
\hline Anion gap (mmol/L) & $7.3^{\downarrow}$ & $7.2^{\downarrow}$ & 11.9 & 14.1 \\
\hline Potassium (mmol/L) & 4.1 & 4.5 & $4.1^{\downarrow}$ & 5.4 \\
\hline Heart rate (bpm) & 117 & 118 & 119 & 120 \\
\hline Mean arterial pressure $(\mathrm{mmHg})$ & 61 & 61 & 64 & 66 \\
\hline Bladder temperature $\left({ }^{\circ} \mathrm{C}\right)$ & 37.1 & 38.0 & $38.3^{\uparrow}$ & $38.5^{\uparrow}$ \\
\hline Noradrenaline ( $\mu \mathrm{g} /$ minute) & 14 & 13 & 12 & 11 \\
\hline
\end{tabular}

bpm beats per minute, $B S$ blood sample, $\mathrm{HCO}_{3}$ bicarbonate, $P \mathrm{PO}_{2}$ partial pressure of carbon dioxide, $P \mathrm{O}_{2}$ partial pressure of oxygen, $\uparrow$ increased value, $\downarrow$ decreased value 


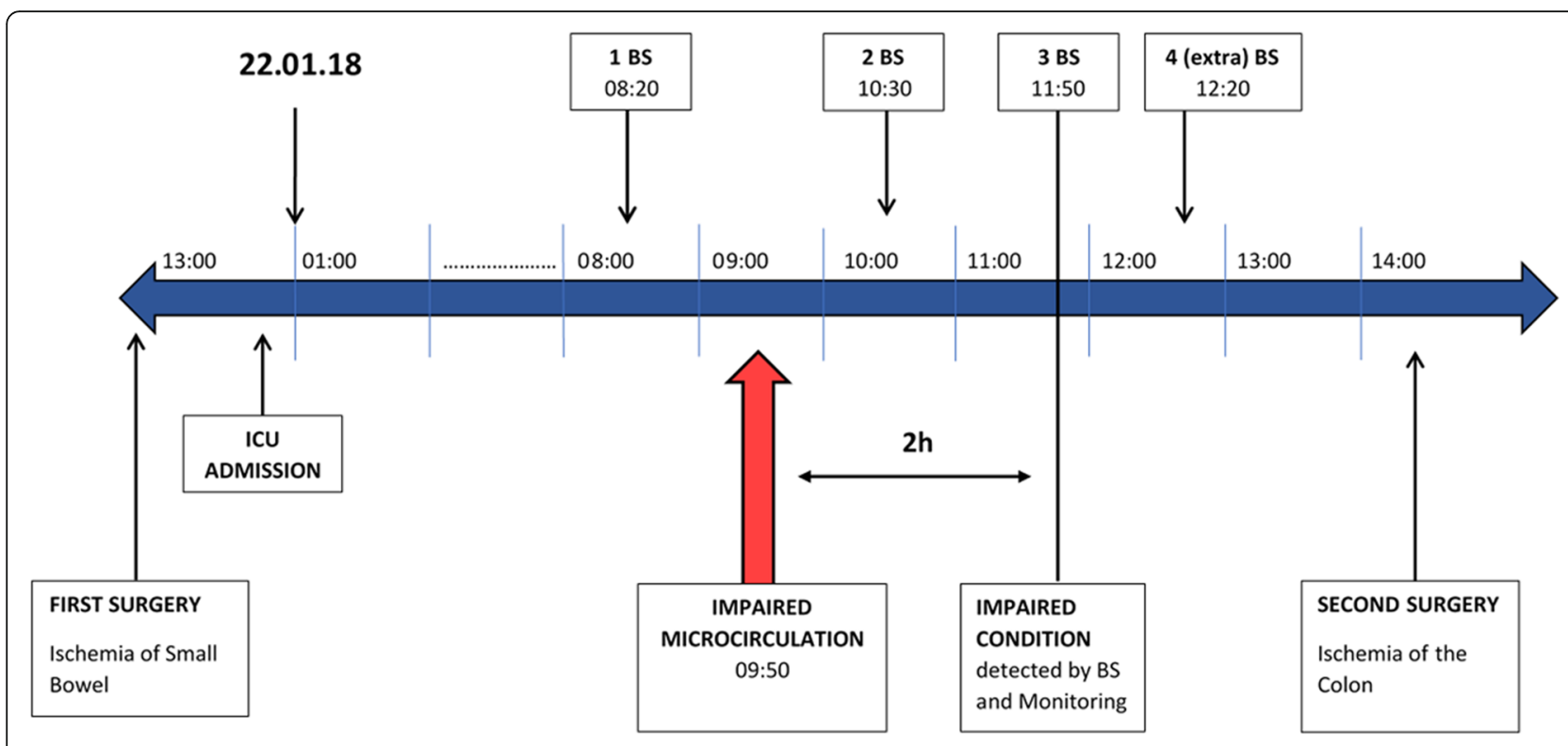

Fig. 4 Timeline of the case since intensive care admission. BS blood sample, ICU intensive care unit

MCF is the key goal in patients with shock, and impaired MCF should at least alert the clinician in charge. Especially, in apparently stable critically ill patients (for example, with sepsis or cardiac failure), a point-in-time measurement in the ICU may help to improve patient management with therapeutic or surgical interventions and detect a critical deterioration earlier. For further study-related purposes, we suggest performing a point-in-time microcirculatory measurement once daily in ICU patients who fulfill one of the following criteria:

- patients dependent on noradrenaline $(>0.2 \mu \mathrm{g} / \mathrm{kg}$ per minute) for circulatory support

- patients dependent on vasopressin

- patients with a skin mottling score $\geq 2$ [11].

From our experience, the measurement is feasible and can be performed by a trained observer at the bedside in less than 5 minutes.

Microcirculation was severely impaired sublingually, even more so in the colon tissue. Although there is no common vascular supply to the tongue and descending colon, we assume that if the sublingual microcirculatory system, which is directly supplied by the carotid arteries and therefore in close proximity to the heart, shows impaired MCF, then capillary regions more distant to the heart are likely to be affected too.

The described case leaves the exact mechanism that led to the altered microcirculation unclear. Data suggest that various mechanisms are involved in the development of impaired microcirculation. Reduced glycocalyx in sepsis promotes adhesion and rolling of leukocytes to the endothelium and reduces blood flow. Increased levels of endotoxins impair backward communication through perivascular nerves to upstream arterioles. Further, endothelial dysfunction with increased capillary leak may lead to relative hypovolemia and altered MCF [12].

Independent from the causative mechanism, observation of the microcirculation in apparently stable ICU patients may help to adjust the therapy or extend diagnostic workup before definitive hemodynamic deterioration.

\section{Conclusion}

In an individual patient, impaired MCF should be taken as a serious warning sign for an imminent deterioration, like a silent canary was for old-time coal miners.

Further research should be conducted to evaluate the value of microvascular blood flow as routine monitoring for apparently stable patients.

\section{Additional files}

Additional file 1: Video S1. Impaired sublingual microcirculation of the described case (recording 1). (MP4 7247 kb)

Additional file 2: Video S2. Intact sublingual microcirculation of a member of the study team. (MP4 $7614 \mathrm{~kb}$ )

\section{Abbreviations}

bpm: Beats per minute; CRP: C-reactive protein; GCS: Glasgow Coma Scale; ICU: Intensive care unit; IDF: Incident dark field; MCF: Microcirculatory flow; MFI: Microvascular flow index; MIQS: Microcirculation image quality score; PPV: Proportion of perfused vessels; PVD: Perfused vessel density;

$\mathrm{SpO}_{2}$ : Blood oxygen saturation; TVD: Total vessel density

Acknowledgements

We thank Allison Dwileski for her support in proofreading. 


\section{Funding}

Author JS has received a research grant "young talents in clinical research" from the "Goldschmidt \& Jacobson foundation" of the University of Basel.

\section{Availability of data and materials}

Most data generated or analyzed during this case report are included in this published article and its supplementary information files. Further data are available from the corresponding author upon request.

\section{Authors' contributions}

JS and MS designed the study and JS collected data. AZ, MS, DY, and JS drafted the report. All authors contributed to intellectual content, review, and revision of the report, and have seen and approved the final version of the manuscript.

\section{Ethics approval and consent to participate}

The underlying study of this case report has been approved by the local ethics committee: Ethikkommission Nordwest- und Zentralschweiz (EKNZ), reference number: EKNZ 2017-01190. Written informed consent for participation was obtained by the patient.

\section{Consent for publication}

Written informed consent was signed by the patient for publication of this case report and accompanying images. A copy of the written consent is available for review by the Editor-in-Chief of this journal.

\section{Competing interests}

The authors declare that they have no competing interests.

\section{Publisher's Note}

Springer Nature remains neutral with regard to jurisdictional claims in published maps and institutional affiliations.

Received: 8 January 2019 Accepted: 9 May 2019

Published online: 12 June 2019

\section{References}

1. Dubin A, Pozo MO, Casabella CA, et al. Increasing arterial blood pressure with norepinephrine does not improve microcirculatory blood flow: a prospective study. Crit Care. 2009;13:R92.

2. Dunser MW, Takara J, Brunauer A, et al. Re-thinking resuscitation: leaving blood pressure cosmetics behind and moving forward to permissive hypotension and a tissue perfusion-based approach. Crit Care. 2013;17:326.

3. Ocak I, Kara A, Ince C. Monitoring microcirculation. Best Pract Res Clin Anaesthesiol. 2016:30:407-18.

4. Dantzker DR. The gastrointestinal tract. The canary of the body? JAMA. 1993:270:1247-8.

5. Aykut G, Veenstra G, Scorcella C, Ince C, Boerma C. Cytocam-IDF (incident dark field illumination) imaging for bedside monitoring of the microcirculation. Intens Care Med Exp. 2015;3:40

6. Sherman H, Klausner S, Cook WA. Incident Dark-Field Illumination: a New Method for Microcirculatory Study. Angiology. 1971;22(5):295-303.

7. Massey MJ, Larochelle E, Najarro G, et al. The microcirculation image quality score: development and preliminary evaluation of a proposed approach to grading quality of image acquisition for bedside videomicroscopy. J Crit Care. 2013;28:913-7

8. De Backer D, Hollenberg S, Boerma C, et al. How to evaluate the microcirculation: report of a round table conference. Crit Care Lond Engl. 2007;11:R101.

9. De Backer D, Donadello K, Sakr Y, Ospina-Tascon G, Salgado D, Scolletta S, Vincent JL. Microcirculatory alterations in patients with severe sepsis: impact of time of assessment and relationship with outcome. Crit Care Med. 2013:41:791-9.

10. Kara A, Akin S, Dos Reis Miranda D, Struijs A, Caliskan K, van Thiel RJ, Dubois EA, de Wilde W, Zijlstra F, Gommers D, Ince C. Microcirculatory assessment of patients under VA-ECMO. Crit Care. 2016:20:344

11. Ait-Oufella $H$, Lemoinne $S$, Boelle $P$, et al. Mottling score predicts survival in septic shock. Intensive Care Med. 2011:37(5):801-7.

12. De Backer D, Orbegozo Cortes D, Donadello K, et al. Pathophysiology of microcirculatory dysfunction and the pathogenesis of septic shock. Virulence. 2014;5(1):73-9.

Ready to submit your research? Choose BMC and benefit from:

- fast, convenient online submission

- thorough peer review by experienced researchers in your field

- rapid publication on acceptance

- support for research data, including large and complex data types

- gold Open Access which fosters wider collaboration and increased citations

- maximum visibility for your research: over $100 \mathrm{M}$ website views per year

At BMC, research is always in progress.

Learn more biomedcentral.com/submission 